\title{
A MEDIAC̣ÃO EDUCATIVA EM UMA ATIVIDADE DE EDUCACุ̃̃O NÃO FORMAL: UMA ANÁLISE SOB A PERSPECTIVA DE SALOMON E PERKINS (1998)
}

\author{
MS. DANIELA CRISTINA LOPES REJAN' * \\ https://orcid.org/0000-0003-1801-8041 \\ PROFA. DRA. MARIANA APARECIDA BOLOGNA SOARES DE ANDRADE ** \\ https://orcid.org/0000-0002-1945-4606
}

RESUMO: A educação não formal é realizada fora da escola, em ambientes nos quais ocorrem ações educativas e onde a figura do mediador é importante no processo de aprendizagem. Ele é responsável, sob supervisão, pela elaboração das atividades, participando da construção de conhecimento. Entretanto, sabe-se que nestas atividades existem obstáculos para que a mediação aconteça. Baseado na perspectiva Vygotskyana de aprendizagem mediada e na proposta de mediação de Salomon e Perkins, o objetivo deste trabalho foi analisar aspectos da mediação de monitores de uma atividade não formal, como identificam seu papel e como a mediação ocorre. Para tanto, a pesquisa, de cunho qualitativo, foi realizada em duas etapas e utilizou dois instrumentos de coleta de dados: questionários eletrônicos e entrevistas semiestruturadas. Os resultados mostram que os mediadores estão longe da ideia de mediação e do seu papel, e que necessitam de formação específica para sua atuação.

Palavras-chave: Educação não formal. Mediação. Mediadores.

\section{MEDIACIÓN EDUCATIVA EN UNA ACTIVIDAD DE EDUCACIÓN NO FORMAL: UN ANÁLISIS DESDE LA PERSPECTIVA DE SALOMON Y PERKINS (1998)}

RESUMEN: La educación no formal se lleva a cabo fuera de la escuela, en entornos donde ocurren acciones educativas y donde la figura del mediador es importante en el proceso de aprendizaje. Él es responsable, bajo supervisión, de la elaboración de actividades, participando en la construcción del conocimiento. Sin embargo, se sabe que en estas actividades hay obstáculos para que ocurra la mediación. Basado en la perspectiva vygotskiana del aprendizaje mediado, y en la propuesta de mediación de Salomon y Perkins, el objetivo

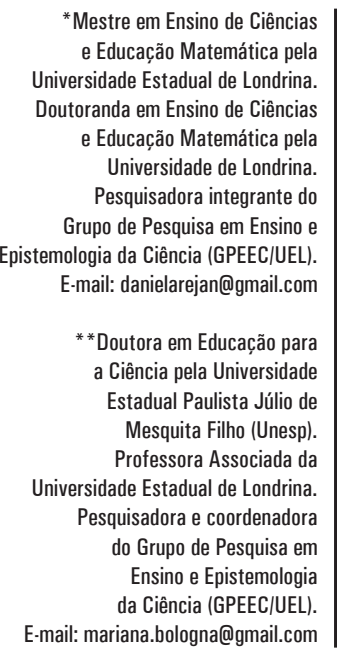

* Mestre em Ensino de Ciências Universidade Estadual de Londrina. utoranda em Ensino de Ciências Educação Matemática pela Universidade de Londrina. Pesquisadora integrante do ologia da Ciência (GPEEC/UEL). mail: danielarejan@gmail.com

Doutora em Educação para Ciência pela Universidade stadual Paulista Júlio de Mesquita Filho (Unesp). Professora Associada da Pesquisadora e coordenadora Grupo de Pesquisa em da Ciência (GPEEC/UEL). E-mail: mariana.bologna@gmail.com 
de este trabajo fue analizar aspectos de la mediación de los monitores de una actividad no formal, cómo identifican su papel y cómo ocurre la mediación. Para ello, la investigación, de carácter cualitativo, se realizó en dos etapas y utilizó dos instrumentos de recolección de datos: cuestionarios electrónicos y entrevistas semiestructuradas. Los resultados muestran que los mediadores están lejos de la idea de la mediación y su papel, y que necesitan capacitación específica para su actuación.

Palabras clave: Educación no formal. Mediación. Mediadores.

EDUCATIONAL MEDIATION IN A NON-FORMAL EDUCATION ACTIVITY: AN ANALYSIS FROM THE PERSPECTIVE OF SALOMON AND PERKINS (1998)

ABSTRACT: Non-formal education is carried out outside school, in environments where educational actions take place and where the figure of the mediator is important in the learning process. He is responsible, under supervision, for the preparation of activities, participating in the construction of knowledge. However, it is known that in these activities there are obstacles to mediation. Based on the Vygotskian perspective of mediated learning and on the proposal of mediation by Salomon and Perkins, the aim of this work was to analyze aspects of the mediation of monitors of a non-formal activity, how they identify their role and how mediation occurs. For that, the research, of qualitative nature, was carried out in two stages and two instruments of data collection were used: electronic questionnaires and semi-structured interviews. The results show that mediators are far from the idea of mediation and its role, and that they need specific training for their performance. Keywords: Non-formal education. Mediation. Mediators. 


\section{INTRODUÇÃO}

A necessidade de alfabetizar cientificamente a população se estende até os dias atuais, mas surgiu dada a necessidade de debater sobre os inúmeros avanços proporcionados à sociedade pela ciência e a tecnologia, e sobre problemas como a degradação ambiental e a má distribuição dos produtos da ciência (ROCHA; TÉRAN, 2010).

Nesse cenário, muitos outros espaços de produção do conhecimento científico começaram a emergir, visto que museus, zoológicos e centros de ciências têm tomado para si a responsabilidade do trabalho de educação científica da população. Assim, considera-se que a educação pode ocorrer em diferentes espaços, denominados pela literatura como espaços de educação formal, não formal e informal (MARANDINO, 2009; CAZELLI, 2005).

É importante salientar que o termo espaço formal diz respeito a um local no qual a Educação ali realizada é formalizada, garantida por lei, relacionada às Instituições Escolares da Educação Básica e definidas, no caso do Brasil, na Lei 9394/96 de Diretrizes e Bases da Educação Nacional. É a escola, com todas as dependências que possui (JACOBUCCI, 2008). Já o termo educação não formal e informal surgiu no final dos anos 1960, nomeando uma educação feita fora do ambiente escolar. Embora já houvesse uma atenção dada às atividades extraescolares, a nova nomenclatura fortaleceu esta maneira de ensinar (LA BELLE, 1982).

Atualmente, há uma discussão em relação ao uso da definição desses termos, porém, mesmo compreendendo que não existe uma definição única e delimitada, para este trabalho vamos utilizar a definição de Vieira (2005) sobre educação não formal: "educação organizada e sistemática fora do ambiente formal de ensino, ela ocorre quando existe a intencionalidade de dados sujeitos em criar ou buscar determinados objetivos fora da instituição escolar" (VIEIRA, 2005, p. 03).

Com foco em espaços da educação não formal, considera-se importante identificar diferentes cenários e intenções de suas atividades. Existem espaços que possuem regulamentação e equipe técnica responsável e capacitada para receber visitantes para conhecer pesquisas, fazer visitas guiadas e, em muitos casos, interagir com o material exposto, como no caso dos museus, parques ecológicos, jardins botânicos, aquários, zoológicos e institutos de pesquisa. Ainda existem os ambientes naturais ou urbanos, que não dispõem desta estrutura institucional, nos quais também são adotadas práticas educativas, como teatros, parques, praças, praias, cinemas dentre outros inúmeros locais (JACOBUCCI, 2008). É importante ressaltar a intencionalidade pedagógica destes espaços pois, existem parques, por exemplo, com e sem essa intencionalidade. No caso de parques e jardins botânicos, além de atividades de educação ambiental, de preservação do meio ambiente, os visitantes, muitas vezes, participam de vivências que despertam a curiosidade e estimulam a contemplação e a reflexão no ambiente natural.

Cabe uma breve discussão sobre espaços formais de ensino que, em atividades pontuais, tornam-se não formais. É o caso de projetos de extensão universitária que, em determinados momentos, recebem a comunidade externa na Universidade em ações que promovam aprendizagem e divulgação científica, como oficinas e visitas às dependências da Universidade. 
Consideramos significativas pesquisas que envolvam atividades de extensão universitária visto que estamos em processo de inserção destas atividades nos currículos de graduação, e este processo não é novo pois o Plano Nacional de Educação (PNE 2001-2010) já instituía a obrigatoriedade de 10\% dos créditos exigidos para os cursos de graduação realizados em ações extensionistas (GADOTTI, 2017).

Já no PNE de 2014-2023 (Lei 13005/2014) esta obrigatoriedade, que propõe atender às políticas públicas nacionais, reaparece na Estratégia 12.7, que compõem a meta 12, assegurando "no mínimo, 10\% (dez por cento) do total de créditos curriculares exigidos para a graduação em programas e projetos de extensão universitária, orientando sua ação, prioritariamente, para áreas de grande pertinência social" (BRASIL, 2014). Pode-se observar, entre o primeiro e o segundo PNE, um importante avanço entre a visão da extensão universitária, visto que o segundo já sustenta uma visão mais popular e emancipatória, colocando como prioridade a atuação em áreas de importância social (GADOT'TI, 2017).

Outro fator que torna esta discussão importante, é o fato de a extensão universitária ser um dos pilares da Universidade, e o trabalho realizado pelos mediadores faz parte de uma ação extensionista interdisciplinar, voltado à transformação social dos alunos participantes do Projeto Novos Talentos. Ações extensionistas desta natureza têm grande importância, também na formação dos graduandos. Para a comunidade externa, os alunos participantes destas ações, o ambiente universitário passa a ser um espaço de ensino não formal, com importante papel de aproximar a comunidade externa do meio acadêmico, dos alunos dos cursos de graduação, inserindo estudantes da educação básica no meio científico e permitindo outros caminhos para a alfabetização científica.

\section{0 MEDIADOR, A MEDIAC̣ÃO NOS ESPAC̣OS DE EDUCAC̦ÃO NÃO FORMAL}

Nos espaços de educação não formal há um personagem significativo na realização das atividades, o monitor, neste trabalho chamado de mediador, mas dependendo de seu papel e do objetivo de cada espaço, pode receber outras nomenclaturas. De qualquer forma, sua presença nos espaços de educação não formal já é algo consolidado (MASSARANI, 2007; SILVA; OLIVEIRA, 2011).

Sob supervisão, é normalmente o responsável pela elaboração de materiais, apresentação de instruções, por mediar as visitas. Em alguns casos, sem o mediador a visita não promoverá o aprendizado esperado, tornando-o um elo significativo entre a atividade, o visitante e a construção de conhecimento.

As formas de atuação do mediador também variam de acordo com a atividade e a instituição em que se inserem. Existem espaços onde além de mediar visitas, os monitores mediadores elaboram exposições, produzem material didático, realizam palestras oficinas, teatros, trilhas e outras atividades (SILVA; OLIVEIRA, 2011). Em sua atuação, o mediador deve ir além dos conteúdos científicos e conhecer aspectos sociais e humanos da ciência, e como se refletem no cotidiano. Também é preciso expressar-se de forma clara e corretamente, evitar atitudes professorais, inferir conhecimentos prévios, a fim de dosar os conteúdos, estimular a curiosidade e conduzir um diálogo reflexivo e interativo com o público, com a finalidade de promover a construção de conhecimento (MATSUURA, 2007). 
Gaspar (1993) apoia-se nas teorias de Vygotsky ao explicar que o mediador deve ser o personagem mais capacitado das interações sociais que ocorrem espontaneamente e, ao priorizar a interação, "falar menos e ouvir mais; perguntar menos e responder mais; preocupar-se menos com o rigor dos conceitos emitidos e mais com a capacidade de compreensão desses conceitos" (GASPAR, 1993, p. 183-184). Sendo assim, em uma atividade de educação não formal, o monitor atua mediando a construção do conhecimento, elabora o conteúdo e o apresenta de forma atrativa, auxiliando os participantes na compreensão do que foi apresentado, e também preocupa-se com o participante, utilizando sua fala para motivá-lo, priorizando o diálogo e a construção do conhecimento.

Sabendo disso, faz-se necessário compreender o conceito de mediação. Na perspectiva Vygotskyana (1988), mediação diz respeito a uma intervenção de um elemento intermediário em uma relação, que deixa de ser direta e passa a ser mediada por este interlocutor. É um processo fundamental para possibilitar a interação entre o indivíduo e seu meio.

Vygotsky afirma que o ser humano se desenvolve essencialmente no ambiente social, e os processos mentais superiores dos indivíduos (pensamento, linguagem, comportamento volitivo, ou seja, comportamento que provém da vontade) têm origem nos processos sociais, desenvolvidos e mediados por instrumentos e signos construídos nos meios social, histórico e cultural nos quais estão inseridos.

De acordo com Moreira (2009), para Vygotsky o desenvolvimento cognitivo não pode ser compreendido sem uma referência ao contexto social e cultural. Entretanto, não é apenas uma questão de considerarmos o meio social uma importante variável nos processos mentais. Na perspectiva Vygotskyana, o desenvolvimento cognitivo caracteriza-se como as relações sociais convertidas em funções mentais. É na socialização que temos o desenvolvimento dos processos mentais superiores, na relação do aluno com o ambiente em que se insere, e não o inverso. (MOREIRA, 2009).

$\mathrm{Na}$ educação não formal, em atividades mediadas, esse desenvolvimento é proporcionado, em grande parte, pela ação do mediador que promove a socialização entre e com os estudantes. Em casos nos quais as atividades são propostas de forma coletiva, a tarefa do mediador é fazer uma ponte entre o que o participante está vivenciando no processo de socialização e um novo conhecimento, seja por meio de atividades pré-elaboradas, de respostas aos participantes ou instigando-os a participar.

Ainda sobre o desenvolvimento cognitivo, Vygotsky chama de Zona de Desenvolvimento Proximal (ZDP) a distância entre o nível real (o que já sabe) do indivíduo e o seu nível potencial (funções que ainda precisam de maior desenvolvimento) (MOREIRA, 1999). Ela define as funções cognitivas que ainda estão no processo de maturação, sendo uma medida do potencial de aprendizagem, representando uma região dinâmica, na qual o desenvolvimento cognitivo ocorre.

Pela leitura de Vygotsky (2003) consideramos o monitor como um mediador necessário. $\mathrm{Na}$ interação social que caracteriza o ensino, são os personagens que já internalizaram significados socialmente compartilhados e que organizam e controlam o meio no qual acontecerão as interações com os participantes. A socialização é a autêntica alavanca do processo educativo, e o papel do monitor consiste em mediá-la. Cabe ressaltar aqui que o mediador também faz parte desse processo, utilizando seu trabalho de mediação para que o desenvolvimento potencial, torne-se o novo real. 
Ainda assim, a socialização pode não acontecer da mesma forma para todos, visto que em uma atividade podem estar inseridos estudantes de diferentes níveis escolares. Está aqui uma das funções importantes do monitor, fazer a mediação entre os diferentes tipos de alunos. Os indivíduos convertem o que aprendem nas relações sociais em funções psicológicas por meio da mediação que, para Vygotsky, é típica da cognição humana. É por intermédio da atividade mediada que se internalizam as atividades (GARTON, 1992).

Apresentados o referencial teórico a respeito da aprendizagem mediada por meio da socialização, segundo a perspectiva de Vygotsky e propomos uma relação com a perspectiva da ação mediadora trazida por Salomon e Perkins (1998). Ao passo que Vygotsky apresenta como se dá a aprendizagem de forma coletiva, estes autores apresentam os tipos de mediação social que podem ocorrer no processo de socialização dos indivíduos.

\section{A PROPOSTA DE MEDIAC̣ÃO DE SALOMON E PERKINS}

Salomon e Perkins adotam uma perspectiva de unificação sobre aprendizagem, na qual diferentes visões podem ser descritas, comparadas. Segundo eles "a ideia de processamento de informações não inclui pressuposições de polarização sobre o lugar em que esses processos são ou a entidade que eles servem" (SALOMON; PERKINS, 1998, p. 3).

Os processos de informação em questão podem ocorrer dentro da mente de um indivíduo ou em redes complexas de interação social. A aprendizagem da entidade pode ser individual ou social, como uma equipe, uma corporação, um grupo de indivíduos soltos ou mesmo uma sociedade. Em qualquer um dos casos, a informação está sendo processada e o aprendizado e o esquecimento ocorrem no sentido de que mudanças duradouras decorrentes do processamento - seja no indivíduo ou em uma entidade social - podem ser identificadas. Para tornar os conceitos mais claros, os autores propõem dois grupos de mediação: a individual e a social.

A mediação individual nos traz a concepção do aprendiz individual, com ênfase na aquisição de conhecimento e de habilidades cognitivas como mercadorias intransferíveis. Salomon e Perkins propõem duas categorias de mediação individual, que são "aprender a ser um aprendiz social" e "aprender conteúdo social". Estas duas categorias não se enquadram nos objetivos desta análise, pois tratam de aprendizagens individuais, e lidam mais com o que é aprendido e diferente da perspectiva Vygotyskiana apresentada neste trabalho (SALOMON; PERKINS, 1998).

Já a mediação social (MS) é aquela que traz a concepção sociocultural da aprendizagem, que trata a construção do conhecimento como um processo coletivo e participativo, com enfoque no contexto do estudante e na interação social, e ainda se referindo aos fatores sociais a serviço da aprendizagem. É aquela na qual os indivíduos se ajudam a aprender (SALOMON; PERKINS, 1998). A mediação social apresentada pelos autores é constituída de quatro categorias que serão apresentadas a seguir.

A primeira categoria, mediação social ativa, reflete estudos referentes ao desenvolvimento cognitivo, tutoria, aprendizagem colaborativa e recíproca etc. A segunda enfatiza a aprendizagem participativa. A terceira categoria trata o papel do mediador e das ferramentas utilizadas no processo de aprendizagem e a última 
trata da aprendizagem envolvendo coletivos como equipes e outras organizações.

$\mathrm{Na}$ sequência, as quatro categorias de mediação social, propostas por Salomon e Perkins (1998) serão detalhadas.

\subsection{MEDIAC̣ÃO SOCIAL ATIVA DA APRENDIZAGEM INDIVIDUAL}

Uma das formais mais fundamentalmente sociais de aprendizagem na sociedade humana é aquela na qual o indivíduo recebe ajuda de uma pessoa ou um grupo para aprender. Por exemplo, um professor que ensina escrita, leitura, ou um pesquisador que assume estagiários e orienta o desenvolvimento destes.

Nesse caso, o agente facilitador (como o professor, o pesquisador) e o aluno, em conjunto, formam um sistema de aprendizagem, no qual o facilitador ajuda o estudante a atingir condições críticas de aprendizagem. Por exemplo, o professor pode fornecer instruções, demonstrações, comentários, tarefas desafiadoras, encorajamento, dicas, sugestões e assim por diante.

A ideia central desse sistema de aprendizagem é a mesma, criar o melhor sistema de aprendizagem para o aluno, trazendo um agente facilitador que, por meio da socialização ajude a atender às condições críticas de aprendizagem, entretanto, as formas adotadas variam de acordo com a necessidade de aprendizagem dos indivíduos (SALOMON; PERKINS, 1998).

Nessa proposta, o sujeito da mediação é o professor ou o monitor, ou seja, o responsável pela mediação. E não se trata de transmissão de determinado conhecimento, mas trata-se do mediador compreender-se como o sujeito que media esse conhecimento, como o sujeito que possibilita a mediação. O papel do professor é auxiliar o estudante a avançar e aprender novas atividades que, sozinho, não conseguiria (MOREIRA, 2009).

No caso de uma atividade de educação não formal executada por mediadores, esse é o tipo de mediação mais comum. Eles são os responsáveis pela mediação quando apresentam um conteúdo dentro das oficinas, orientam alguma atividade prática, orientam o planejamento da equipe de monitores. Neste caso, estão criando um sistema de aprendizagem para o estudante, facilitando o aprendizado.

\subsection{MEDIAC̣ÃO SOCIAL COMO CONSTRUC̣ÃO PARTICIPATIVA DO CONHECIMENTO}

No tópico anterior, existe uma clara distinção entre os indivíduos, os sujeitos que vão aprender e os agentes sociais que facilitam essa aprendizagem. Mas há uma segunda versão de mediação social que merece reconhecimento: a versão sociocultural, que vê o aprender mais como uma questão de estar inserido e participar de um processo social de construção do conhecimento do que como a aquisição de conhecimento e habilidade socialmente facilitada. Os exemplos podem ser os mesmos, tutoria individual, resolução de problemas em grupo, aprendizado colaborativo, mas a maneira como são compreendidos nesta segunda versão é muito diferente.

Aqui, a mediação social do aprendizado e o indivíduo envolvido são vistos como um sistema integrado, que utiliza da interação como veículo dos pensamentos socialmente compartilhados. Assim, os produtos de aprendizagem são construídos em conjunto, e distribuídos por todo o sistema ao invés de estarem 
em posse apenas do aluno participante (SALOMON; PERKINS, 1998).

Nesta proposta entende-se que há mais de um sujeito responsável pela mediação, o professor e o estudante. O professor elabora atividades nas quais ele será o mediador, mas que alunos também possam mediar conhecimento de outras pessoas. O mediador e o aluno formam um sistema de aprendizado, e o que importa, neste caso, é o conhecimento que será construído nessa interação, a longo prazo.

\subsection{MEDIAC̣ÃO SOCIAL POR ANDAIMES CULTURAIS}

Mesmo quando um estudante não recebe ajuda direta de outro personagem que se ajusta ativamente às suas necessidades, como na primeira proposta de mediação, ele pode estabelecer algum tipo de parceria intelectual, ou ao menos ser ajudado por artefatos culturais, na forma de ferramentas e fontes de informação.

Esses artefatos, ou andaimes, podem variar de livros até ferramentas estatísticas e sistemas simbólicos compartilhados de forma social, incorporando por exemplo uma linguagem de pensamento. Os artefatos são cultural e historicamente situados, levando a sabedoria e os pressupostos que fizeram parte de seu desenvolvimento, formando assim um sistema de aprendizagem com o aluno, reorganizando e determinando o que pode ser realizado, podendo mudar quando, onde, em que forma e até a finalidade (SALOMON; PERKINS, 1998).

Podemos chamar de artefatos, ou andaimes, as atividades elaboradas para execução das propostas em espaços de educação não formal. Neste caso, o papel do mediador é fornecer e até mesmo elaborar os artefatos, quando necessários, ajustando o material às necessidades dos estudantes. Este tipo de mediação relaciona-se diretamente com o primeiro tipo proposto pelos autores, visto que trata do trabalho realizado pelo professor ou monitor.

\subsection{A ENTIDADE SOCIAL COMO UM SISTEMA DE APRENDIZAGEM}

A aprendizagem social ganha um outro significado, muito diferente, quando falamos de aprendizagem envolvendo equipes, organizações, culturas e outros coletivos. Neste caso, não é necessariamente apenas um agente ajudando e o outro aprendendo. O foco da aprendizagem cai sobre um coletivo que, por ser coletivo, adquire mais conhecimento, compreensão ou habilidade, ou um clima ou cultura diferentes.

Em resumo, o grupo constitui um sistema de aprendizagem coletivo, um sistema que funcionará melhor ou pior como aprendiz, dependendo de quão bem suas estruturas abordem condições críticas de aprendizagem. Em espaços de educação não formal, muitas vezes por conta da falta de tempo para que este sistema de aprendizagem se construa, este tipo de mediação não é encontrado, pois além do tempo requerer um comprometimento do grupo que não é possível de ocorrer em atividades esparsas (SALOMON; PERKINS, 1998).

A mediação social, apresentada nas quatro categorias, proposta por Salomon e Perkins (1998) pode ser resumida na figura a seguir: 
Figura 1. Esquema da proposta de mediação de Salomon e Perkins (1998)

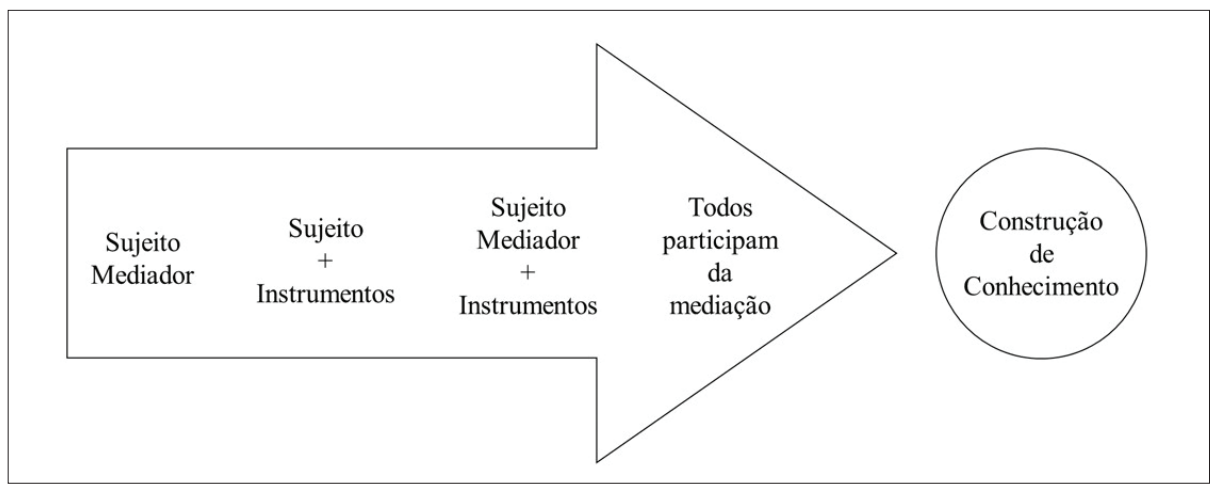

Fonte: As autoras.

Essa proposta pode ser entendida como uma mediação que parte de um sujeito mediador, de um sujeito que utiliza instrumentos, de um sujeito mediador que usa instrumentos e possibilita que a mediação seja realizada por outros sujeitos, até que se chegue em um nível de independência no qual todos os sujeitos participem da mediação e da construção do conhecimento.

Com o aumento dessa independência, o grau dos sujeitos mediadores também aumenta. Entretanto, todos os processos podem acontecer nos espaços de ensino, uns mais que os outros, e é importante ressaltar que um nível não anula o outro. Dentre as propostas de atividade, os diferentes níveis podem apresentar suas vantagens em função de tempo, espaço, número de sujeitos, necessidades de aprendizagem, objetivos educacionais.

Diante do referencial teórico apresentado, retomamos aqui os questionamentos que nos levaram a iniciar esta pesquisa. Analisando uma proposta de atividade de educação não formal, realizada no ambiente universitário, por mediadores alunos de cursos de graduação e pós-graduação, é possível encontrar, nos relatos destes mediadores, características que aproximem a mediação realizada à proposta de Salomon e Perkins (1998)?

Esse questionamento leva ao objetivo geral desta pesquisa, que é analisar aspectos da mediação de monitores de uma atividade de educação não formal. Como objetivos específicos elencamos: (i) analisar como os monitores identificam seu papel como mediador nas ações do Projeto e (ii) analisar se as mediações propostas por Salomon e Perkins (1998) foram desenvolvidas pelos mediadores e de que maneira.

\section{PROCEDIMENTOS METODOLÓGICOS}

Esta pesquisa teve uma abordagem qualitativa pois buscou com mediadores de uma atividade de extensão universitária sua fonte de dados e os investigadores como instrumento principal de análise (BOGDAN; BIKLEN, 1994). Apresentaremos inicialmente o contexto do projeto desenvolvido em uma universidade pública do Estado do Paraná, no qual os mediadores atuavam como monitores e, posteriormente, os procedimentos metodológicos. 
O Projeto Novos Talentos é um projeto de extensão universitária, que surgiu em 2011, com o objetivo de oferecer oficinas com foco na construção do conhecimento e trazendo a estudantes da Educação Básica a oportunidade de compreender temas das ciências naturais por meio de experimentos, teatros, jogos e outras atividades lúdicas, aproximando-se de atividades de educação não formal. Ao longo desta pesquisa foram realizadas três edições das oficinas, em duas os temas abordados foram Anatomia Comparada, Biologia Celular e Histologia, Neurociência, Sistema Reprodutor e Sexualidade e Zoonoses. Na outra oficina os temas das atividades foram Biotecnologia e Microbiologia, Botânica, Drogas e Sociedade, Fisiologia e Nutrição e Zoologia. Cada oficina teve duração de cinco sábados, os alunos da educação básica eram divididos em cinco grupos no primeiro dia de oficina e cada grupo passava por uma oficina diferente por semana.

As oficinas tinham dois tipos de monitores, os fixos das oficinas (29) e os que acompanhavam os alunos (10). Os monitores participantes desta pesquisa foram os fixos das oficinas pois estes não só elaboraram as atividades como também eram os responsáveis pelo seu desenvolvimento. Os 29 monitores voluntários eram estudantes de cursos de graduação e pós-graduação de cursos das áreas biológicas, agrárias e da saúde, entre 18 e 27 anos de idade. Deste total, oito participaram do projeto pelo menos uma vez quando eram alunos da educação básica e 19 já haviam participado pelo menos uma vez como mediadores. Todos os participantes desta pesquisa assinaram um Termo de Consentimento Livre e Esclarecido (TCLE).

A pesquisa envolveu o que Chizzotti (2006) define como coleta sistemática de informações, utilizando questionário e entrevista semiestruturada. A análise dos questionários e da entrevista foi feita por categorização (BARDIN, 2011). Os dados do questionário foram organizados em unidades de Contexto e registro a posteriori. A análise da entrevista foi realizada de forma flutuante, ou seja, buscamos encontrar na fala dos entrevistados aspectos das categorias propostas por Salomon e Perkins (1998), alocando-as nas categorias elaboradas a priori. As categorias propostas também foram compostas por Unidades de Registro (UR), que emergiram a posteriori, mediante a leitura dos trechos das entrevistas. Este processo nos permitiu discutir os questionamentos que levaram a esta pesquisa.

Em um primeiro momento, os dados foram coletados por meio de questionário eletrônico (via Google Docs) e respondido antes do início das atividades do projeto. Deste questionário foram utilizadas neste artigo duas perguntas: 1- Como você define o papel do monitor no tipo de atividade que realizamos?, referese ao papel do mediador no projeto. 2- O que é mais importante levar em consideração ao elaborar uma atividade para o Projeto?, que envolve aspectos e critérios que o mediador considera importantes na elaboração do material.

Em um segundo momento, entre a segunda e a quinta semana de atividades, foram realizadas entrevistas com dezesseis mediadores. Optamos pelas entrevistas pois segundo Silveira (2002), configura-se como uma interação social em que tanto o entrevistador como o entrevistado atuam na produção dos conhecimentos. Podemos dizer que uma pesquisa que utiliza entrevistas é uma interação social, na qual o principal meio de troca são as palavras.

O roteiro de entrevistas foi elaborado em função de cada item proposto por Salomon e Perkins (1998). Categoria1, o mediador auxilia na aprendizagem 
do estudante formando com este um sistema. Foram propostas duas perguntas: 1- Escolha uma atividade elaborada por você e faça uma avaliação de como ela transcorreu. Como você avalia esta atividade? 2- Quais foram suas ações para que os alunos compreendessem o conteúdo? Você teve que agir de formas diferentes pelo fato de os alunos serem de séries diferentes?

Categoria 2, trata da construção do conhecimento como sendo um processo participativo e coletivo: 1- Você consegue identificar se houve aprendizagem por parte dos alunos? Explique como isso ocorreu. 2- A interação que existe entre os alunos e na relação com o mediador serviu como veículo para a aprendizagem? Explique.

Categoria 3, aborda a mediação por meio dos andaimes culturais, ou seja, os materiais e atividades elaborados: 1- Como foi o processo de elaboração das atividades? 2- Quais fatores foram levados em consideração para escolher as atividades utilizadas?

A última categoria apresentada pelos autores não se constitui como uma categoria de análise porque envolve um sistema coletivo que constrói a aprendizagem em um período mais longo de tempo, como equipes e grandes organizações.

\section{RESULTADOS E DISCUSSÃO}

Os resultados foram divididos em dois momentos. No primeiro, apresentaremos a discussão dos dados coletados por meio dos questionários eletrônicos, pelos quais buscamos obter percepções dos mediadores a respeito de seu papel e de aspectos relacionados à elaboração dos materiais e atividades realizadas no Projeto Novos Talentos.

No segundo momento, serão discutidos os resultados dos dados coletados por meio das entrevistas, com os quais buscamos fazer relações com as propostas de Salomon e Perkins (1998), evidenciando aspectos da mediação.

\section{ANÁLISE DOS QUESTIONÁRIOS}

Para a análise dos questionários eletrônicos foram elencadas duas perguntas, as respostas permitiram a elaboração de duas Unidades de Registro (UC) e suas Unidades de Registro (UR).

\subsection{UC1: PAPEL DO MEDIADOR}

Esta Unidade foi organizada em quatro Unidades de Registro (UR), que tratam das percepções sobre o papel do mediador nas atividades oferecidas pelo Projeto Novos Talentos, como demonstra o quadro abaixo. 
Quadro 1. Unidades de Registro da UC1.

\begin{tabular}{|c|c|}
\hline \multicolumn{2}{|l|}{ UC1. Papel do Mediador } \\
\hline \multirow[b]{2}{*}{$\begin{array}{l}\text { UR1.1. Transmitir ou compartilhar } \\
\text { conhecimentos, experiências }\end{array}$} & 11 registros \\
\hline & $\begin{array}{l}\text { Fundamental, o monitor transmite conhecimentos } \\
\text { para os alunos não apenas científico, mas também de } \\
\text { experiências vividas, além disso, os alunos se sentem } \\
\text { mais próximos e desinibidos quando conversam com } \\
\text { os monitores (M01) }\end{array}$ \\
\hline \multirow[b]{2}{*}{$\begin{array}{l}\text { UR1.2. Contato com a } \\
\text { Universidade e o conhecimento } \\
\text { produzido nela }\end{array}$} & 10 registros \\
\hline & $\begin{array}{l}\text { O monitor é o responsável pela construção de } \\
\text { uma ponte que liga a comunidade científica com a } \\
\text { comunidade externa à universidade, levando aos } \\
\text { alunos os produtos de pesquisas em ciência (M09) }\end{array}$ \\
\hline \multirow{2}{*}{$\begin{array}{l}\text { UR1.3. Cria vínculos, interage e } \\
\text { mantém contato com os alunos }\end{array}$} & 2 registros \\
\hline & $\begin{array}{l}\text { Decisiva, pois são eles que fazem o projeto acontecer } \\
\text { e eles são quem interage com os alunos (M20) }\end{array}$ \\
\hline \multirow{2}{*}{ UR1.4. Não contempla a questão } & 6 registros \\
\hline & Responsabilidade (M21) \\
\hline
\end{tabular}

Fonte: As autoras.

Nesta Unidade de Contexto esperava-se que os mediadores relatassem sua percepção sobre o papel do mediador nas atividades do projeto. Os resultados demonstram que a maior parte acredita que o papel do mediador é transmitir conteúdos, conhecimentos e compartilhar experiências. Também vemos uma visão engessada, de que o conhecimento compartilhado é pronto, e não construído pelo estudante. Neste ponto, consideramos negativos estes resultados, pois esta visão do conhecimento não pode fazer parte da fala do mediador que, muitas vezes repete o tipo de ensino que recebeu na educação básica e no ensino superior.

Outro grupo significativo de sujeitos acredita que seu papel é o de ser um ponto de contato com o ambiente universitário, fazendo a aproximação dos estudantes com a Universidade. Ainda deste grupo, três dos sujeitos afirmaram que um dos papéis é o de mediador, entre o aluno e a Universidade. Sabendo que a extensão universitária é um dos pilares da Universidade, é por meio destes projetos, que se voltam para as transformações sociais dos estudantes, e do contato com os mediadores que estes têm a oportunidade de conhecer um novo ambiente, do qual também tem direito de fazer parte.

Um grupo menor de sujeitos afirma que o papel do mediador é criar vínculos e ter contato com os estudantes participantes, corroborando com Gaspar (1993), quando este afirma que o mediador deve ser essencial nas interações sociais provocadas por ele ou que ocorrem espontaneamente, priorizar o diálogo e a interação social.

Mesmo os resultados apontando que os mediadores compreendem como sendo seu papel compartilhar o conhecimento produzido no ambiente universitário, 
ser um ponto de contato entre este e os estudantes, também podemos observar um problema, pois vemos que a concepção de mediação ainda está longe daqueles que a executam na prática, visto que este pensamento de conhecimento pronto não pode fazer parte da visão do mediador.

\subsection{UNIDADE DE CONTEXTO 2 (UC2): ASPECTOS PARA ELABORAÇÃO DE ATIVIDADES}

Esta Unidade foi organizada em quatro UR, que abordam aspectos que os mediadores levam em consideração durante o processo de elaboração de uma atividade para as oficinas. O quadro abaixo apresenta exemplos de respostas referentes a cada Unidade de Registro.

Quadro 2. Unidades de Registro da UC2.

\begin{tabular}{|c|c|}
\hline \multicolumn{2}{|c|}{ UC2. Aspectos para elaboração de atividades } \\
\hline \multirow[b]{2}{*}{ UR2.1. Conteúdo científico } & 11 registros \\
\hline & $\begin{array}{l}\text { Acredito que o mais importante é a relação da atividade } \\
\text { com o conteúdo abordado nas oficinas. Assim, as } \\
\text { atividades não parecem que foram apenas realizadas } \\
\text { aleatoriamente para preencher tempo, mas sim, com um } \\
\text { objetivo claro de ensino (M17) }\end{array}$ \\
\hline \multirow[b]{2}{*}{ UR2.2. Centrado no aluno } & 10 registros \\
\hline & $\begin{array}{l}\text { Deve-se pensar se é uma atividade que o aluno consiga } \\
\text { entender levando em conta seu conhecimento prévio, } \\
\text { para que consiga realizá-la, tentando também, de alguma } \\
\text { forma, deixar essa atividade divertida de se fazer (M10) }\end{array}$ \\
\hline \multirow[b]{2}{*}{ UR2.3. Metodologia } & 6 registros \\
\hline & $\begin{array}{l}\text { Pensar em formas didáticas de explicar os conteúdos } \\
\text { trabalhados, usando uma linguagem clara e fácil de ser } \\
\text { compreendida, sem deixar informações importantes para } \\
\text { trás (M22) }\end{array}$ \\
\hline \multirow[b]{2}{*}{ UR2.4. Não contempla a questão } & 2 registros \\
\hline & A avaliação do conteúdo e a integração da turma (M16) \\
\hline
\end{tabular}

Fonte: As autoras.

Nesta Unidade esperava-se que os mediadores elencassem aspectos que consideram importantes ao elaborar atividades que serão desenvolvidas com os alunos participantes do Projeto.

A análise das respostas mostra que a maioria dos sujeitos estão alocados na UR2.1, pois afirmam que o conteúdo científico é o aspecto mais importante, levantando-se outros como aplicabilidade e relevância do conteúdo, se está presente no cotidiano dos alunos e se será eficaz na compreensão dos conteúdos. 
O segundo maior grupo de respostas (UR2.2) agrupa sujeitos que afirmam que relatam aspectos relacionados ao aluno, como conhecimentos prévios, as idades e séries dos alunos e aplicabilidade em seu dia a dia.

Levando-se em conta os instrumentos e atividades utilizados na mediação, a Unidade de Registro 2.2 corrobora com o afirmado por Carletti (2016), quando o autor enfatiza que estes devem ser pensados e elaborados tendo em vista o tipo de visitantes, no caso, os estudantes participantes, suas necessidades e seus interesses, para que a mediação ocorra de forma satisfatória.

Os sujeitos agrupados na Unidade de Registro 2.3 dão maior importância à metodologia utilizada na atividade, relatando a importância da criatividade na concepção de atividades lúdicas, interessantes e formas eficientes de oferecer os conteúdos aos alunos, utilizando linguagem clara e de fácil compreensão. Os resultados desta unidade corroboram com algumas das características que Matsuura (2007) traz como sendo importantes no papel do mediador, quando este afirma que ele deve saber dosar conteúdos, estimular a curiosidade dos alunos e ter senso lúdico.

Esse grupo de respostas ainda aponta a visão conteudista dos mediadores, que demonstram muita preocupação com o conteúdo e menor preocupação com aspectos relacionados à habilidade dos estudantes e à possibilidade de elaborar uma atividade que desperte o pensamento crítico. Não está centrado no aluno e, enquanto este não for o centro desta elaboração das atividades, a mediação não será realizada de maneira efetiva.

\section{ANÁLISE DAS ENTREVISTAS}

Neste momento analisamos os dados coletados mediante as entrevistas, realizadas com uma parcela significativa dos sujeitos, escolhidos segundo critérios já apresentados na metodologia deste trabalho.

A análise permitiu a elaboração, a posteriori, de várias Unidades de Registro, que foram alocadas em Unidades de Contexto estabelecidas a priori, de acordo com as categorias propostas por Salomon e Perkins (1998).

\subsection{CATEGORIA 1 (C1) - MEDIACÃO SOCIAL ATIVA DA APRENDIZAGEM INDIVIDUAL}

Esta categoria ampara-se nas explicações de Salomon e Perkins (1998) que tratam da aquisição de conhecimento socialmente facilitada. Aqui buscamos a relação estabelecida pelo mediador com o aluno, formando um sistema de aprendizagem. Dessa forma, as questões envolviam a avaliação de uma atividade mediada pelo entrevistado e pelo relato dos mediadores a respeito de mudanças ou adequações que foram feitas para facilitar a mediação e, consequentemente, o aprendizado do estudante.

Nesta categoria foram organizadas duas unidades de registro. A UR 1: mediação gerando motivação no aluno teve cinco registros. Apresentamos o trecho da resposta do mediador M09:

[...] eu acho que foi boa, porque os alunos demonstraram bastante interesse, a gente teve um retorno muito bom. Na primeira semana alguns alunos vieram falar que 
gostaram bastante e acho que para alguns deles foi muito bom porque foi o primeiro contato ali com microscópio, eles colocaram a mão na massa, se sujaram de corante, eu acho que foi bem legal.

A segunda unidade de contexto UR 2: Mediação voltada a contextualização teve 12 registro, abordou a preocupação do mediador em adequar a linguagem ao público, como demonstra o trecho de M18:

E passei mais ou menos para o vocabulário do dia a dia deles, sem palavra muito complicada e quando falava alguma palavra complicada eu ia e explicava de um jeito mais apropriado para eles, como eles iam entender e tudo mais.

Nessa categoria esperava-se que os mediadores fornecessem respostas que se reconhecessem como sujeitos que possibilitam a mediação. A ocorrência dessa percepção foi possível em ambas unidades de registro. Além desse aspecto, pode-se perceber que para esses monitores a mediação priorizou a motivação dos participantes e a contextualização das atividades

Os mediadores demonstram compreender, de forma incipiente, que são sujeitos responsáveis no processo de aprendizagem, pois não existe uma preocupação prévia com a preparação das atividades. Ainda de acordo com o proposto por Salomon e Perkins (1998), é possível identificar que houve mediação.

\subsection{CATEGORIA 2 (C2) - MEDIAÇÃO SOCIAL COMO CONSTRUC̣̃̃O DE CONHECIMENTO PARTICIPATIVO}

Salomon e Perkins (1998) também apresentam a aprendizagem como a participação em um processo social de construção de conhecimento. Buscamos nos trechos analisados da fala dos mediadores, encontrar relações entre a interação aluno-aluno e aluno-mediador com a aprendizagem proporcionada por meio destas interações e da mediação. Da análise das respostas foram organizadas três unidades de registro.

A UR1: interação que gera motivação, três registros. Na perspectiva desta unidade, os monitores salientaram a importância da coletividade para gerar a motivação entre os participantes, como aponta M04:

Ah eu acho que sim, ainda mais quando os monitores dos módulos têm que ter uma maior receptividade para o aluno se sentir à vontade pra perguntar. Porque às vezes eles tem uma dúvida, mas ficam com medo de perguntar, então se eles não conseguem ter essa interação entre eles, eles não se sentirem à vontade, também fica esse medo de perguntar. Então eu acho que é importante, às vezes um acaba incentivando o outro, ou numa conversa entre eles surge uma dúvida que às vezes não surgiria antes, e aí vem a pergunta, e aí você consegue aprender mais.

A UR2: interação focada no monitor, nove registros. Nesta unidade foram consideradas as respostas dos participantes que indicaram que o monitor fazia parte do coletivo composto entre participantes e eles, como indica a fala de M19: 
Eles sentem que os monitores não são professores, eles sentem que os monitores são parte deles, eles são parte da turma, então a abordagem é diferente do que numa sala de aula. Eu sei porque eu sou professora, então eu vejo muito essa diferença. Então o jeito que eles sentem liberdade para perguntar coisas pra gente, eles acabam conhecendo muito mais coisas do que se ele estivesse numa sala de aula, porque eles têm mais liberdade para perguntar

A UR3: interação entre os alunos obteve cinco registros. Nesta unidade foram selecionadas as respostas e que os monitores identificaram o papel da mediação que ocorre entre os sujeitos ao longo das atividades, assim como explicado por M17:

Entre eles dá para ver bastante que eles começam a discutir muitas vezes, às vezes até discordam ou um fica falando uma coisa o outro fala outra coisa que ele acha que acrescenta, então eu acho que essa discussão também auxilia eles a aprenderem um pouco mais.

Nessa categoria era esperado que emergissem trechos que apontassem a mediação como construção de algum conhecimento novo, coletivamente, e socialmente realizado. $\mathrm{Na}$ análise, foi possível inferir que nenhum dos mediadores tem noção desta mediação proposta por Salomon e Perkins (1998), que trata da construção de conhecimento participativo. Os mediadores são capazes de identificar a interação que ocorre entre eles e os alunos, e entre os próprios alunos, entretanto, ainda mostra indícios de uma mediação unilateral, a interação não contribui para a construção de um conhecimento novo.

\subsection{CATEGORIA 3 (C3) - MEDIAC̣̃̃O SOCIAL POR ANDAIMES CULTURAIS}

Aqui buscamos compreender a relação do mediador com os andaimes, também chamados de artefatos, que elabora para suas atividades. Segundo Salomon e Perkins (1998), os artefatos elaborados pelo mediador formam uma parceira intelectual com o estudante, auxiliando-o na aprendizagem. Para tanto, as questões eram referentes ao processo de elaboração das atividades e fatores utilizados para escolher os artefatos utilizados.

Nessa categoria emergiram três unidades de registro. Na UR1: elaboração de atividade em contexto diferente do da escola, foram registradas três respostas nas quais os monitores indicaram que para elaborar atividades o objetivo era diferenciá-las daquelas da escola, assim como indicado por M23:

Tentar não fazer muito o que eles fazem dentro da sala de aula, tentar trazer de uma maneira diferente, mais animada (...) Então, a gente tentou fazer de uma forma que a gente conseguisse participar e que os alunos conseguissem também.

Na UR2: elaboração em função do aluno, tiveram três registros e foram agrupadas as respostas dos monitores que indicaram a preocupação de organizar produtos que os alunos se identificassem e se interessassem, como apresentado por M22:

Ah era aquilo assim... "se eu tivesse como aluno eu iria gostar de ter isso? De ter essa atividade?" 
E a gente procurou ao máximo fugir do ambiente da sala de aula, evitar muita aula expositiva porque a botânica é um assunto complicado para você ficar dando muita matéria. Então a gente pensou assim: "se eu tivesse a idade deles eu iria entender com isso? I gostar de fazer, por exemplo, uma atividade fora da sala uma aula expositiva?

$\mathrm{Na}$ última unidade de registro estão as respostas de 12 monitores. $\mathbf{N a}$ UR3: elaboração em função de conteúdo, foram agrupadas as respostas dos monitores que indicaram ter priorizado o conteúdo para a elaboração das atividades, assim como dito por M04:

Os temas a gente pensou mais na questão do vestibular, coisas que cairiam no vestibular, então a gente achou importante, porque às vezes, por exemplo, os biomas são temas que eles veem muito pouco e cai no vestibular. E a gente queria fazer coisas divertidas assim, ai vem uma ideia "ah vamos fazer xadrez", "ah mas o xadrez é assim..." foi indo, foi aquele brainstorm, você vai jogando, cada um pega uma coisa e no final das contas vira um só.

Nessa categoria, esperávamos encontrar nas falas dos mediadores características consideradas importantes no momento de elaboração dos materiais, ou artefatos, utilizados durante as atividades do Projeto Novos Talentos.

Os resultados encontrados mostram que a grande maioria dos mediadores se restringe apenas ao conteúdo, neste momento do trabalho, elaborando atividades extremamente conteudistas, baseadas em provas de vestibulares, ao volume e à absorção do mesmo.

A Categoria reforça os dados provenientes do questionário inicial, que mostrou a distância que ainda existe entre a visão de mediação e a fala dos mediadores entrevistados. E apresenta uma situação preocupante: a grande maioria dos mediadores leva em consideração o conteúdo para elaborar os artefatos das atividades.

De acordo com o referencial apresentado, para uma mediação mais efetiva, o mediador deve considerar o estudante como centro tanto do planejamento, como da execução das atividades, e a maioria dos relatos dos sujeitos não indica esta situação.

\section{CONSIDERAC̣ÕES FINAIS}

Este trabalho teve como objetivo a análise de aspectos relacionados à mediação realizada em uma atividade de educação não formal. Mais especificamente, analisamos como os monitores identificam seu papel como mediador e se as mediações propostas por Salomon e Perkins (1998) foram desenvolvidas e de que maneira. O referencial teórico foi apoiado nos aspectos referentes aos espaços de educação não formal, à mediação e ao mediador, e na proposta de mediação de Salomon e Perkins (1998).

A análise dos dados obtidos nos questionários, coletados antes do início das atividades, mostrou que a percepção dos mediadores está bem distante da ideia de mediação e que os mediadores ainda estão muito voltados ao conteúdo específico e à proposta de ensino conteudista.

Quanto à análise do papel do mediador, a maior parte dos resultados mostra ser papel do mediador transmitir conteúdo. Apresenta também uma visão 
engessada de que o conhecimento compartilhado é pronto e acabado, não sendo uma construção individual, de cada estudante. Podemos considerar negativo este resultado, pois este tipo de pensamento não pode estar presente na fala do mediador, que, muitas vezes, repete o ensino que recebeu durante sua formação. Já uma outra parcela dos resultados mostra que o papel do mediador é ser um ponto de contato entre a Universidade e os participantes da atividade.

Ainda consideramos que, mesmo que não seja feita referência à mediação na fala dos sujeitos, podemos inferir que os mediadores não se enxergam nesta função, como facilitadores do processo de aprendizagem e da construção de conhecimento.

A respeito da análise dos aspectos levados em consideração durante a elaboração das atividades, os resultados continuam sendo referentes ao conteúdo, mesmo os que apontam a importância da metodologia ou de aspectos que envolvam o aluno. Aqui identificamos novamente uma visão conteudista dos mediadores que, na construção da oficina, demonstraram preocupação com o conteúdo, e a quantidade dele, e menor ênfase em outros aspectos relacionados aos participantes, em despertar sua curiosidade e interesse pela Ciência. Enquanto o estudante não for o centro do planejamento, a mediação não será realizada de forma eficaz.

Já na análise das entrevistas, realizadas após a primeira semana de atividades, os resultados foram agrupados nas categorias propostas por Salomon e Perkins (1998). Quanto à mediação social ativa da aprendizagem individual, foram encontrados discursos referentes à mediação motivadora do aluno e mediação voltada à contextualização. Podemos inferir que os mediadores percebem a necessidade de adequar as atividades em função dos estudantes, porém, nota-se que esta percepção ainda é superficial, e surgiu somente no momento de execução das atividades, sendo que, para promover a mediação de forma mais efetiva, deveria ter ocorrido no momento do planejamento.

Aqui emergiu um dado preocupante, pois os mediadores, por não terem essa percepção prévia, preocupam-se apenas com o momento da atividade, e não com o processo como um todo. Ainda assim, é possível identificar que houve mediação, e que os entrevistados se percebem como responsáveis pela aprendizagem, diferindo do dado apresentado nos questionários eletrônicos.

Também ficou demonstrado que nenhum dos mediadores encaixa-se na proposta de Salomon e Perkins (1998), quando se trata da mediação social como construção de um conhecimento participativo. Mesmo sendo capazes de identificar as interações, os mediadores ainda mostram indícios de uma mediação unilateral e, portanto, de uma não contribuição da interação para a construção de um conhecimento novo.

Sobre a mediação apoiada em andaimes, apesar de julgarem importante diferenciar-se do contexto escolar, a maior parte dos mediadores fica restrita apenas ao conteúdo no momento de elaboração dos materiais, baseando-se no seu volume e profundidade, e também nos conteúdos importantes para futuros vestibulares dos estudantes.

Nota-se que atividades como as propostas no Projeto carecem de discussões e preparação dos mediadores para que compreendam a potencialidade da mediação tanto para a elaboração das atividades como para o desenvolvimento das mesmas. A mediação já deve estar contida nos objetivos estabelecidos para projetos como 
o estudado neste trabalho, pois, parte importante de projetos em espaços de educação não formal é abordar conhecimento científico de maneira diferenciada da concepção conteudista e transmissiva, ainda presente em muitas escolas.

Além disso, este trabalho mostrou que estudantes de diferentes cursos têm interesse em atividades extensionistas, e a preparação destes torna-se significativa visto os currículos de muitos cursos universitários não contemplarem este tipo de formação. Uma breve análise das ementas dos cursos representados pelos sujeitos mostrou que nenhum possui disciplinas relacionadas à extensão universitária, o que permite inferir que os sujeitos não têm uma preparação específica para a atuação extensionista durante todo o curso, o que aponta para a necessidade de novas pesquisas que, além de identificar percepções de mediadores, permitam momentos de formação dos mesmos.

\section{AGRADECIMENTOS}

À coordenação e à equipe do Projeto Novos Talentos pelo auxílio na coleta dos dados, à Coordenação de Aperfeiçoamento de Pessoal de Nível Superior (CAPES), pelo aporte financeiro a esta pesquisa, através da bolsa de mestrado da pesquisadora e também aos revisores da Ensaio pelas sugestões.

\section{REFERÊNCIAS BIBLIOGRÁFICAS}

BARDIN, L. Análise de conteúdo. $4^{a}$ ed. Lisboa: Edições, v. 70, p. 1977, 2011.

BOGDAN, R.; BIKLEN, S. K. Investigação Qualitativa em Educação. Portugal: Porto Editora, 1994.

BRASIL. Lei n. 13.005, de 25 de jun. de 2014. Plano Nacional de Educação. Brasília, DF, jun. 2014. Disponível em: <http://www.planalto.gov.br/ccivil_03/_ato2011-2014/2014/lei/113005. htm>. Acesso em: 18 jan. 2019.

CARLETTI, C. Mediadores de Centros e Museus de Ciências brasileiros: quem são esses atores-chave na mediação entre a ciência e o público? 2016. 119 f. Tese (Doutorado) - Programa de Pós-graduação em Ensino em Biociências e Saúde, Instituto Oswaldo Cruz, Rio de Janeiro, 2016.

CAZELLI, S. Ciência, cultura, museus, jovens e escolas: Quais as relações? 2005. 260 f. Tese (Doutorado) - Programa de Pós-graduação em Educação, Pontifícia Universidade Católica do Rio de Janeiro, Rio de Janeiro, 2005.

CHIZZOTTI, A. Pesquisa qualitativa em ciências humanas e sociais. Petrópolis, RJ. Vozes, 2006.

GADOTTI, M. Extensão universitária: para quê? Instituto Paulo Freire, 2017.

GARTON, A. F. Social interaction and the development of language and cognition. Hillsdale, NJ: Lawrence Erlbaum Associates, 1992.

GASPAR, A. Museus e Centros de Ciências -: conceituação e proposta de um referencial teórico. 1993. 118 f. Tese (Doutorado) - Faculdade de Educação, Universidade de São Paulo, São Paulo, 1993. 
JACOBUCCI, D. F. C. Contribuições dos espaços não formais de educação para a formação da cultura científica. Em Extensão, Uberlândia, v. 7, p.55-66, 2008.

LA BELLE, T. J. Formal, nonformal and informal education: a holistic perspective on lifelong learning. International Review of Education. 1982.

MARANDINO, M. Museus de Ciências, Coleções e Educação: relações necessárias. Museologia e Patrimônio, Rio de Janeiro, v. 2, n. 2, p.01-12, jul/dez 2009.

MASSARANI, L. (org.). Diálogos \& Ciência: mediação em museus e centros de Ciência. Rio de Janeiro: Casa de Oswaldo Cruz/Fiocruz, p. 56-67. 2007.

MATSUURA, O. T. Teatro cósmico: mediação em planetários. In: MASSARANI, L. (org.). Diálogos \& Ciência: mediação em museus e centros de ciência. Rio de Janeiro: Casa de Oswaldo Cruz/ Fiocruz, p. 76-80. 2007.

MOREIRA, M. A. Subsídios Teóricos para o Professor Pesquisador em Ensino de Ciências: comportamentalismo, construtivismo e humanismo. Porto Alegre: UFRGS, 2009.

MOREIRA, M. A. Teorias de aprendizagem. São Paulo: Editora pedagógica e universitária, 1999.

ROCHA, S. C. B. da; TERÁN, A. F. O uso de espaços não-formais como estratégia para o ensino de Ciências. Manaus: UEA Edições, 136 p. 2010.

SALOMON, G.; PERKINS, D. N. Chapter 1: Individual and social aspects of learning. Review of research in education, v. 23, n. 1, p. 1-24, 1998.

SILVA, C. S. da; OLIVEIRA, L. A. A. de. Mediadores de Centros de Ciências e os seus papéis durante as visitas escolares. Ensaio, Belo Horizonte, v. 13, n. 2, p.47-64, maio 2011.

SILVEIRA, R. M. H. A entrevista na pesquisa em educação - uma arena de significados. In: COSTA, M. V. (org.) Caminhos Investigativos II - outros modos de pensar e fazer pesquisa em educação. Rio de Janeiro: DP\&A, 2002.

VIEIRA, V. da S. Análise de espaços não-formais e sua contribuição para o ensino de Ciências. 2005. 205 f. Tese (Doutorado) - Instituto de Bioquímica Médica, Universidade Federal do Rio de Janeiro, Rio de Janeiro, 2005.

VYGOTSKY, L. S. Pensamento e Linguagem. $4^{a}$ ed. São Paulo: Martins Fontes, 2003.

VYGOTSKY, L. S. A formação social da mente. $2^{a}$ ed. brasileira. São Paulo: Martins Fontes, 1988.

Submetido em 19/01/2020

Aprovado em 14/05/2020

\section{Contato:}

Universidade Estadual de Londrina (UEL)

Programa de Pós-graduação em Ensino de Ciências e Educação Matemática - PPECEM

Rodovia Celso Garcia Cid, PR 445, Km 380. Campus Universitário.

Cx. Postal 10.011 | CEP 86.057-970 - Londrina, PR - Brasil 